\title{
Competitividad en las organizaciones de productores de aguacate en Sucre, Colombia*
}

Cómo citar este artículo : Ramírez García, A. G., y Pérez Peralta, C. M. (2018). Competitividad en las organizaciones de productores de aguacate en Sucre, Colombia.Cuadernos de Desarrollo Rural, I5 (8I), I-23. https://doi.org/I0.III44/Javeriana.cdri5-8I.copa

Adán Guillermo Ramírez García

Universidad Autónoma Chapingo , México

gramirezg@taurus.chapingo.mx

ORCID: http://orcid.org/0000-0002-I7II-5942

Claudia Milena Pérez Peralta

Corporación Universitaria del Caribe (Cecar), Colombia

ORCID: http://orcid.org/ 0000-0002-3799-9642

DOI: https://doi.org/10.III44/Javeriana.cdri5-8I.copa

Redalyc: http://www.redalyc.org/articulo.oa?id=I1757604005

Recibido: 23 Mayo 2017 I Publicación: 18 Junio 20I8

\section{Resumen:}

La competitividad de las organizaciones de productores campesinos de aguacate en los municipios de Ovejas, Colosó y Chalán, del departamento de Sucre en Colombia, desde el análisis de la competitividad organizacional, fue evaluada en este trabajo. El objetivo fue alcanzado a partir de un estudio descriptivo correlacional, una metodología cuantitativa y un método inductivo analítico, cuya fuente de información fue un cuestionario realizado en las cuatro organizaciones estudiadas. Los resultados indican que las organizaciones productoras de aguacate estudiadas en Sucre tienen bajos niveles de competitividad, lo que imposibilita su entrada al mercado internacional.

Palabras clave: competitividad, competitividad organizacional, organización de productores campesinos, aguacate.

\section{Competitiveness in the Avocado Producer Organizations in Sucre, Colombia}

\begin{abstract}
This work evaluates the competitiveness among the avocado peasant producer organizations in the villages of Ovejas, Colosó and Chalán, in the Colombian province of Sucre, under the organizational competitive analysis. The objective was accomplished based on a correlational descriptive study - which is both a quantitative methodology and an analytical inductive method- with a questionnaire applied to the four studied organizations as the source of information. The results indicate that the studied avocado-producing organizations in the Sucre province have low competitiveness levels, which makes them impossible to tap into the international market.
\end{abstract}

Keywords: competitiveness, organizational competitiveness, peasant producer organization, avocado 


\section{Introducción}

La teoría sobre la competitividad en el pensamiento económico tiene sus primeros antecedentes desde las tesis mercantilistas del siglo XVII, y fue Mun, en I895, uno de los primeros en reconocer que el aumento en las exportaciones de un país (reino) es fundamental para crear riqueza. Según los mercantilistas, la acumulación de metales preciosos solo se obtenía desde una balanza comercial superavitaria. Las naciones se enriquecían a costa de los otros países, en lo que Smith (1776) llamaría un siglo más tarde "la política de 'empobrecer al vecino (beggar the neighbour)'”. El pensamiento de los mercantilistas es resumido por el ensayista Michel de Montaigne (citado en Brue y Grant, 2009, p. I4) como "la utilidad de un hombre es el daño de otro". Bajo este movimiento, la riqueza de los países no radicaba ni en la producción ni en la acumulación de bienes de capital, sino, más bien, en un excedente de exportaciones (Mun, I895).

Desde este enfoque, esta corriente de pensamiento planteó una relación circular entre la riqueza y el poder; es decir, la riqueza era un medio para mantener o incrementar el poder, pero, a su vez, el poder era lo que garantizaba la adquisición o retención de la riqueza. El mercantilismo estableció una estrecha asociación entre la balanza comercial y la balanza de poder. Adam Smith (1776, citado en Escribano, 1999) criticó duramente la percepción mercantilista del comercio internacional, pues, para él, el comercio debía considerarse como un lazo de unión entre países, y no como una fuente de conflicto; propuso que cada nación viese "las riquezas de las [naciones] vecinas como una causa y ocasión probable para acumular riquezas ella misma” (p. 3).

En el entorno global actual, la visión de Smith prevalece toda vez que el comercio internacional se plantea como ventajoso para el desarrollo de los países; en este escenario, las naciones, para poder competir y obtener beneficios, necesitan desarrollar sus ventajas competitivas; durante el desarrollo de estas ventajas, la medición de la competitividad como tal es un tema importante, pues la medición permite comparar, de manera robusta y estandarizada, no solo el desempeño de las empresas, sino también el desarrollo de regiones o países desde la visión de su plataforma productiva, por lo que es un insumo básico para la formulación de la política pública. Estas mediciones constituyen información útil no solo para determinar fortalezas y debilidades de las firmas, regiones o países, sino para contribuir a la implementación de estrategias que apalanquen una mayor competitividad (Consejo Privado de Competitividad [CPC] y Centro de Pensamiento en Estrategias Competitivas de la Universidad del Rosario [Cepec], 2013).

Parece existir una relación entre el crecimiento económico y la competitividad de los países, donde generalmente naciones con altos grados de crecimiento en su renta tienen altos niveles de competitividad, a pesar de que existe otra serie de variables que inciden en este fenómeno, y la relación entre crecimiento y competitividad existe. Según Sachs y Vial (2002), una clave importante para el éxito en el crecimiento económico en la actualidad es la adecuada inserción en la economía mundial; es decir, los países que comercian menos con el resto del mundo y cuyo comercio exterior es muy dependiente de la exportación de productos básicos tienden a crecer menos.

Según las teorías del crecimiento endógeno, la evidencia empírica ha permitido identificar variables para el crecimiento de los países, tales como la tasa de inversión en capital fijo, la ausencia de corrupción, un buen clima político y la no dependencia económica exclusiva de recursos naturales y de sectores primarios, así como el grado de apertura comercial (Sachs y Warner, 1995, 200I); de esta forma, se considera el comercio en los mercados extranjeros no como una fuerza centrífuga al crecimiento de los países, sino como una fuerza centrípeta que tienen los estados nacionales para poder desarrollarse internamente, desde el aprovechamiento del escenario externo.

Para el adecuado aprovechamiento del escenario internacional, es fundamental el desarrollo de ventajas competitivas, concepto que es un constructo inmerso en una idea más amplia, la idea de la competitividad. La competitividad es un término complejo y multidimensional sobre el cual no existe una definición única (Saavedra, 
20I2; Solleiro y Castañón, 2005). Según la Real Academia de la Lengua Española (1992), el concepto se define desde dos acepciones: la capacidad de competir y la rivalidad para la consecución de un fin; a pesar de estos dos acentos, la palabra competitividad etimológicamente proviene del vocablo competencia, el cual solo se enfoca en la segunda acepción, es decir, se entiende como la "oposición o rivalidad entre dos o más que aspiran a obtener la misma cosa”; teniendo en cuenta esto, la competitividad se puede asociar como la capacidad para competir, en particular, de las firmas (Abdel y Romo, 2005), dado que son las empresas las que compiten, y no los países o territorios (Bejarano, 1995).

La competitividad, desde el punto de vista micro, es un fenómeno multidimensional que abarca variados aspectos de distinta naturaleza; en su estimación, involucra variables tanto cualitativas como cuantitativas. Específicamente a nivel de empresa, la competitividad está asociada con variables como la rentabilidad, la productividad, los costos, el valor agregado, la participación de mercado, las exportaciones, la innovación tecnológica y la calidad de los productos, entre otras (McFetridge, 1995).

Rojas y Sepúlveda (1999) identifican, a nivel micro, variables que inciden en la competitividad de las organizaciones, como la productividad, los costos, los esquemas de organización, la innovación con tecnologías limpias, la gestión empresarial, el tamaño de la firma, las prácticas culturales en el campo, el tipo de tecnologías usadas, las conciencia ambiental, la diversificación y el control de calidad de los productos, el avance en esquemas de comercialización y las distancias entre fuentes de materias primas, empresas y mercados.

Cabrera, López y Ramírez (20II), por su parte, plantean que las variables a tener en cuenta al momento de cuantificar el nivel de competitividad de una firma son la innovación, el capital intelectual (equipo humano), la calidad, la tecnología, el conocimiento del mercado, la investigación y el desarrollo, la asociatividad (entendida como alianzas estratégicas o relaciones de cooperación con otras empresas), las estrategias empresariales, la diferenciación, la productividad, los precios, la gestión financiera, la cultura organizacional y el servicio. Por otro lado, McFetridge (1995, citado en Ubfal, 2004) considera que la competitividad puede ser medida desde variables como los costos laborales unitarios, las cuotas de mercado y la productividad total de los factores. Ubfal (2004) menciona que las variables que inciden en la competitividad de las empresas están ligadas a la estructura de mercado y a la estrategia que tenga la empresa para aumentar su cuota de mercado y, por ende, sus beneficios económicos. Dichas variables son presentadas en la tabla i:

TABLA 1

VARIABLES QUE CUANTIFICAN LA COMPETITIVIDAD DE LAS FIRMAS

\begin{tabular}{|c|c|c|c|c|}
\hline Tipo de Sector & Fuentes & Mecanismo & Resultado & Objetivo \\
\hline $\begin{array}{l}\text { Bienes homogéneos- } \\
\text { competencia perfecta }\end{array}$ & $\begin{array}{l}\text { Eficiencia, economías de escala y } \\
\text { costos }\end{array}$ & Costos medios & \multirow{4}{*}{$\begin{array}{l}\text { Mayor cuota de } \\
\text { mercado }\end{array}$} & \multirow{4}{*}{$\begin{array}{c}\text { Valor } \\
\text { presente de } \\
\text { beneficios }\end{array}$} \\
\hline Bienes diferenciados & Publicidad, activos intangibles e I\&D & $\begin{array}{l}\text { Atractivo del } \\
\text { producto }\end{array}$ & & \\
\hline Mercados segmentados & $\begin{array}{l}\text { Capacidad y rapidez de adaptación y } \\
\text { acceso a mercados }\end{array}$ & $\begin{array}{c}\text { Flexibilidad } \\
\text { productiva }\end{array}$ & & \\
\hline $\begin{array}{l}\text { Alta intensidad } \\
\text { tecnológica }\end{array}$ & $\begin{array}{l}\text { I\&D, interacción, aprendizaje y } \\
\text { acceso a capital de riesgo }\end{array}$ & Innovación & & \\
\hline
\end{tabular}

Fuente: elaboración propia con base en Ubfal (2004) 
En el caso de las organizaciones campesinas, como una tipología de agremiación definida por la economía social $^{[1]}$ (Pérez, Etxezarreta y Guridi, 2009), la visión de la competitividad dista del tradicional enfoque de la empresa privada, debido a que mientras la naturaleza de la firma particular es generar réditos sobre el capital invertido, en las organizaciones campesinas de tipo asociación existe una clara preeminencia de las personas, es decir, del bienestar colectivo, sobre el capital y la generación de ganancias (Chaves, Monzón y Sajardo, 200z; Monzón, 2003). La competitividad de este tipo de organizaciones sociales, se puede definir como la capacidad del ente para responder de forma eficiente no solo a las necesidades del mercado, sino a las necesidades y capacidades de sus asociados. En particular, la competitividad sería la habilidad o capacidad que tienen estas asociaciones para adaptarse y desarrollar sus objetivos, en mercados multicontexto, generando beneficios para el colectivo y desarrollo socioeconómico en los contextos donde actúen.

Según Narváez-Rodríguez (20I4), las asociaciones de productores rurales se entienden como organizaciones que acopian a un conjunto de campesinos -agricultores, ganaderos, etcétera- que comparten circunstancias comunes, como la región o subregión donde están asentados o los tipos de cultivo; estas organizaciones se forman principalmente con el objetivo de optimizar el estado de las unidades productivas asociadas al mejorar su nivel de negociación frente a sus clientes o proveedores, formar alianzas con distintos estamentos públicos o privados o mejorar el acceso a recursos económicos o financieros. Por su parte, las cooperativas rurales, según este mismo autor, son definidas como empresas de propiedad común cuyo objetivo es la producción, comercialización, transformación y distribución de bienes y servicios, para lo cual compiten con firmas privadas en el mercado. Tanto las cooperativas como las asociaciones tienen fines sociales, en los que los excedentes se reinvierten en la organización o se destinan a proyectos comunitarios.

Cualquiera de estas organizaciones, para lograr ser competitiva en el mercado mundial, debe desarrollar procesos de gestión estratégicos basados en un enfoque multisectorial y una orientación abierta, conectada y contextualizada a situaciones particulares del ámbito global, tales como: grados de fragmentación y concentración de industrias, surgimiento de nuevos mercados, mayor sentido de responsabilidad social, generación de cadenas internacionales de valor agregado, ética empresarial frente a los problemas medioambientales y mayor sentido del valor social compartido; frente a estos retos, es fundamental desarrollar una adecuada gestión, la cual, en este tipo de organizaciones, se hace de forma concertada por el colectivo, para lo cual es indispensable crear lazos de confianza y una mayor construcción de capital social (Dávila, 2003). Según Bastidas (2005), la ventaja competitiva de este tipo de agremiaciones radica precisamente en su comportamiento de "organización-sujeto", pues la gestión se hace de forma concertada para satisfacer de manera simultánea no solo el bienestar individual, sino el general.

Las organizaciones estudiadas en la presente investigación no se pueden catalogar como cooperativas, dado que no fueron desarrolladas de manera autónoma por parte de campesinos que querían formar empresa de propiedad común para producir y comercializar sus productos, sino que su origen está ligado a las posibilidades de acceso de la población campesina víctima, a recursos y al apoyo del Estado; la gestión de estas organizaciones en la región se da desde la intervención de distintas instituciones gubernamentales y no gubernamentales que intervinieron el territorio, y los productores campesinos que las conforman comparten circunstancias comunes -regiones, cultivos, estado de vulnerabilidad y afectación por el conflicto armado, entre otras-, circunstancias que, precisamente, son las que prevalecen en el nacimiento de la organización.

En la investigación se definió una serie de objetivos, de los cuales el central fue: I) determinar el nivel de competitividad en las organizaciones productoras de aguacate en el departamento de Sucre, con base en la construcción de un índice sintético de competitividad. Para lograr esto, se debió caracterizar la estructura y las áreas organizacionales de las organizaciones de productores campesinos de aguacate; se identificaron los factores de competitividad de estas organizaciones en el departamento estudiado y, finalmente, se propusieron estrategias para generar condiciones competitivas en la producción y comercialización de aguacate en el departamento de Sucre, con miras al mercado internacional. 


\section{Metodología}

Los objetivos de esta investigación fueron alcanzados a partir de un estudio descriptivo correlacional, una metodología cuantitativa y un método inductivo analítico, cuya fuente de información fundamental fue primaria, y un cuestionario fue el instrumento para obtener los datos. El cuestionario fue dirigido a los administradores de organizaciones campesinas productoras de aguacate en el departamento de Sucre; fueron en particular tres municipios y cuatro organizaciones: dos, en el municipio de Ovejas, una, en el municipio de Chalán, y una, en el municipio de Colosó. Esto, con el fin de obtener una batería de indicadores que permitieran valorar el nivel de competitividad de las organizaciones de productores de aguacate desde la construcción de un indicador sintético, basado en la metodología del mapa de competitividad del Banco Interamericano de Desarrollo (BID).

Estas organizaciones, que se dedican a producir y comercializar productos agropecuarios, tienen entre 29 y 250 asociados. Los nombres de las asociaciones de productores son: Aprot, de la vereda El Tesoro, y Asovichengue, del corregimiento Chengue, ambas en el municipio de Ovejas; la Asociación de Productores Agropecuarios del Caribe, en Chalán, y la Asociación de Víctimas de Chinulito, en el corregimiento de Chinulito, zona rural de Colosó.

\section{Naturaleza de los datos}

Los datos con los que se trabajó provinieron de una fuente de información primaria y de un cuestionario de encuesta aplicado en las cuatro organizaciones productoras de aguacate de la región, llamada Caribe Húmedo, en el departamento de Sucre. El cuestionario contó con siete módulos, los cuales fueron:

a) identificación e información general,

b) función administrativa y toma de decisiones,

c) función gerencial y de gestión,

d) función económica y financiera,

e) función de servicios a los asociados y a la comunidad,

f) función de capital social y desarrollo humano y

g) el mapa de competitividad del BID.

Cabe destacar que las primeras seis partes del instrumento cuantifican el índice de capacidad organizacional (ICO), y en la última parte se plantea el mapa del BID, con lo que se obtiene el índice de competitividad empresarial (ICE).

El ICO es un instrumento metodológico diseñado por el Departamento Nacional de Planeación (DNP) en Colombia con el propósito de establecer la capacidad de gestión de las organizaciones comunitarias de los programas de paz y desarrollo a nivel nacional. El ICO, debido a su buen desempeño para identificar las debilidades y fortalezas de las organizaciones, ha sido ajustado por varias entidades, tanto públicas como privadas, para ser aplicado en diferentes tipos de organizaciones (Programa de las Naciones Unidas para el Desarrollo [PNUD] y Área de Desarrollo, Paz y Reconciliación [Redes], 20I2) (tabla 2, 2a, 2b, 2c, 2d, 2e, 2f, 2g). El mapa del BID tiene originalmente I24 preguntas dirigidas a cada una de las áreas y subáreas de la empresa (planeamiento estratégico, cadena de valor, aseguramiento de la calidad, comercialización, mercado de exportación, contabilidad y finanzas, talento humano, gestión ambiental y sistemas de información) y califica de $\circ$ a 5 el nivel en el que esta se encuentra (Montoya y Silvestre, 2008). 
TABLA 2

ÍNDICE DE CAPACIDAD ORGANIZACIONAL (ICO)

\begin{tabular}{|c|c|c|c|c|}
\hline Tema & Categorías & Indicadores & Opciones de respuesta & Ponderación \\
\hline \multirow{31}{*}{$\begin{array}{l}\text { Manejo democrático y } \\
\text { participativo }\end{array}$} & \multirow{7}{*}{ Junta administradora } & \multirow{2}{*}{ Confirmación } & Completa & 1 \\
\hline & & & Incompleta & 0 \\
\hline & & \multirow{3}{*}{ Frecuencia de reuniones } & De acuerdo con los estatutos & 2 \\
\hline & & & Esporádicamente & 1 \\
\hline & & & No se reúne & 0 \\
\hline & & \multirow{2}{*}{ Actas y registros } & Llevan actas & 1 \\
\hline & & & No llevan & 0 \\
\hline & \multirow{7}{*}{$\begin{array}{l}\text { Funcionamiento de } \\
\text { las asambleas }\end{array}$} & \multirow{3}{*}{ Frecuencia de reuniones } & Por lo menos 2 veces al año & 2 \\
\hline & & & Menos de 2 veces al año & 1 \\
\hline & & & No se reúne & 0 \\
\hline & & \multirow{2}{*}{ Número de socios asistentes } & Más del $50 \%$ & 1 \\
\hline & & & Menos del 50\% & 0 \\
\hline & & \multirow{2}{*}{ Actas y registros } & Sí & 1 \\
\hline & & & No & 0 \\
\hline & \multirow{8}{*}{ Participación } & \multirow{3}{*}{ Conocimiento de estatutos } & Más de la mitad & 2 \\
\hline & & & Menos de la mitad & 1 \\
\hline & & & Ninguno & 0 \\
\hline & & \multirow{3}{*}{ Comités conformados } & Más de 3 & 2 \\
\hline & & & Menos de 3 & 1 \\
\hline & & & Ninguno & 0 \\
\hline & & \multirow{2}{*}{ Comunicación } & Órgano de difusión propio & 1 \\
\hline & & & No usan ninguno & 0 \\
\hline & \multirow{9}{*}{ Base social } & \multirow{3}{*}{ Planeación participativa } & Con representantes o socios & 4 \\
\hline & & & La junta directiva & 1 \\
\hline & & & Gerente & 0 \\
\hline & & \multirow{3}{*}{ Toma de decisiones } & Con representantes o socios & 4 \\
\hline & & & La junta directiva & 1 \\
\hline & & & Gerente & 0 \\
\hline & & \multirow{3}{*}{ Información de decisiones } & Socios & 4 \\
\hline & & & La junta directiva & 1 \\
\hline & & & Gerente & 0 \\
\hline \multirow{15}{*}{$\begin{array}{l}\text { Situación económica y } \\
\text { financiera }\end{array}$} & \multirow{8}{*}{$\begin{array}{l}\text { Patrimonio de la } \\
\text { asociación }\end{array}$} & \multirow{3}{*}{ Sede } & Propia y/o comodato & 4 \\
\hline & & & En arriendo & 3 \\
\hline & & & No tiene & 0 \\
\hline & & \multirow{3}{*}{ Muebles y equipos (mayoria) } & Propia y/o comodato & 4 \\
\hline & & & En arriendo & 3 \\
\hline & & & No tiene & 0 \\
\hline & & \multirow[t]{2}{*}{ Otros bienes } & Tiene & 4 \\
\hline & & & No tiene & 0 \\
\hline & \multirow{7}{*}{ Capital de trabajo } & & Solo recursos propios & 6 \\
\hline & & Tor th 10 & Solo recursos propios y externos & 6 \\
\hline & & ruente de los recursos & Solo recursos externos & 3 \\
\hline & & & No tiene & 0 \\
\hline & & & Creciente & 7 \\
\hline & & Comportamiento de los recursos & Constante & 5 \\
\hline & & & Decreciente & 0 \\
\hline
\end{tabular}


TABLA 2 (cont.)

ÍNDICE DE CAPACIDAD ORGANIZACIONAL (ICO)

\begin{tabular}{|c|c|c|c|c|}
\hline Tema & Categorías & Indicadores & Opciones de respuesta & Ponderación \\
\hline \multirow{32}{*}{$\begin{array}{l}\text { Capacidad gerencial, } \\
\text { administrativa y de gestión }\end{array}$} & \multirow{11}{*}{ Gerencia } & \multirow{2}{*}{ Plan de acción } & Tiene & 3 \\
\hline & & & No tiene & 0 \\
\hline & & \multirow{2}{*}{$\begin{array}{l}\text { Mecanismo de evaluación de la } \\
\text { gestión }\end{array}$} & Sí evalúa & 1 \\
\hline & & & No evalúa & 0 \\
\hline & & \multirow{2}{*}{ Plan de negocios } & Tiene & 2 \\
\hline & & & No tiene & 0 \\
\hline & & \multirow{2}{*}{ Recursos humanos contratados } & Tiene & 1 \\
\hline & & & No tiene & 0 \\
\hline & & \multirow{3}{*}{ Manejo de computadores } & Más de uno & 2 \\
\hline & & & Solo uno & 1 \\
\hline & & & Ninguno & 0 \\
\hline & \multirow{11}{*}{ Administración } & \multirow{2}{*}{ Informes financieros y contables } & Llevan informes & 4 \\
\hline & & & No los llevan & 0 \\
\hline & & \multirow{2}{*}{ Cuenta bancaria } & Sí & 1 \\
\hline & & & No & 0 \\
\hline & & \multirow{2}{*}{ Obligaciones tributarias al día } & Sí & 1 \\
\hline & & & No & 0 \\
\hline & & \multirow{3}{*}{ Pérdidas y ganancias } & Creciente & 2 \\
\hline & & & Estable & 1 \\
\hline & & & No tiene o decreciente & 0 \\
\hline & & \multirow{2}{*}{ Órganos de control } & Sí & 1 \\
\hline & & & No & 0 \\
\hline & \multirow{10}{*}{ Gestión } & \multirow{2}{*}{ Gestión en los últimos tres años } & Sí & 2 \\
\hline & & & No & 0 \\
\hline & & \multirow{2}{*}{ Proyectos aprobados } & Uno o más & 1 \\
\hline & & & Ninguno & 0 \\
\hline & & \multirow{3}{*}{$\begin{array}{l}\text { Realización con otras } \\
\text { organizaciones }\end{array}$} & Con más de una & 2 \\
\hline & & & Con solo una & 1 \\
\hline & & & Con ninguna & 0 \\
\hline & & \multirow{3}{*}{$\begin{array}{l}\text { Suscripción de contratos con } \\
\text { entidades públicas o privadas }\end{array}$} & Más de un contrato & 2 \\
\hline & & & Solo un contrato & 1 \\
\hline & & & Ningún contrato & 0 \\
\hline
\end{tabular}


TABLA 2 (cont.)

ÍNDICE DE CAPACIDAD ORGANIZACIONAL (ICO)

\begin{tabular}{|c|c|c|c|c|}
\hline Tema & Categorías & Indicadores & Opciones de respuesta & Ponderación \\
\hline \multirow{18}{*}{$\begin{array}{l}\text { Servicios ofrecidos a } \\
\text { asociados, a la comunidad } \\
\text { o a terceros }\end{array}$} & \multirow{6}{*}{$\begin{array}{l}\text { Servicios } \\
\text { financieros y } \\
\text { comerciales }\end{array}$} & \multirow{3}{*}{ Financieros } & Más de dos modalidades & 3 \\
\hline & & & Una sola modalidad & 2 \\
\hline & & & No tiene & 0 \\
\hline & & \multirow{3}{*}{ Comerciales } & Más de dos modalidades & 3 \\
\hline & & & Una sola modalidad & 2 \\
\hline & & & No tiene & 0 \\
\hline & \multirow{9}{*}{$\begin{array}{l}\text { Servicio de } \\
\text { capacitación y } \\
\text { asistencia técnica }\end{array}$} & \multirow{3}{*}{ De información } & Sí tiene más de un servicio & 2 \\
\hline & & & Sí tiene solo uno & 1 \\
\hline & & & No presta & 0 \\
\hline & & \multirow{3}{*}{$\begin{array}{l}\text { Servicios técnicos en pedidos a } \\
\text { los socios }\end{array}$} & Sí tiene más de un servicio & 2 \\
\hline & & & Sí tiene solo uno & 1 \\
\hline & & & No presta & 0 \\
\hline & & \multirow{3}{*}{ De capacitación } & Sí tiene más de un servicio & 2 \\
\hline & & & Sí tiene solo uno & 1 \\
\hline & & & No presta & 0 \\
\hline & \multirow{3}{*}{ Otros servicios } & \multirow{3}{*}{ Servicios sociales } & Sí tiene más de un servicio & 3 \\
\hline & & & Sí tiene solo uno & 2 \\
\hline & & & No presta & 0 \\
\hline \multirow{15}{*}{$\begin{array}{l}\text { Habilidades y capacidades } \\
\text { en el desarrollo humano }\end{array}$} & \multirow{3}{*}{$\begin{array}{l}\text { Capacitación y } \\
\text { sensibilización }\end{array}$} & \multirow[t]{3}{*}{ Capacitación recibida } & Más de dos & 2 \\
\hline & & & Una & 1 \\
\hline & & & Ninguna & 0 \\
\hline & \multirow{7}{*}{$\begin{array}{l}\text { Dinámicas de } \\
\text { cooperación y } \\
\text { conflicto }\end{array}$} & \multirow[t]{2}{*}{ Relaciones con la comunidad } & Cooperación & 2 \\
\hline & & & Conflicto o no tiene & 0 \\
\hline & & \multirow{2}{*}{$\begin{array}{l}\text { Relaciones internas de la } \\
\text { asociación }\end{array}$} & Cooperación & 1 \\
\hline & & & Conflicto & 0 \\
\hline & & \multirow[t]{3}{*}{ Relación con el estado } & Cooperación & 2 \\
\hline & & & Conflicto en resolución & 1 \\
\hline & & & Conflicto no resulto & 0 \\
\hline & \multirow{5}{*}{ Equidad de género } & \multirow{3}{*}{$\begin{array}{l}\text { Participación y toma de } \\
\text { decisiones }\end{array}$} & $\begin{array}{l}\text { Hombres y mujeres en cargos de } \\
\text { decisión }\end{array}$ & 2 \\
\hline & & & Mujeres solo como socias & 1 \\
\hline & & & No participan & 0 \\
\hline & & \multirow{2}{*}{$\begin{array}{l}\text { Programas dirigidos a la familia } \\
\text { y/o a las mujeres }\end{array}$} & Sí tienen & 1 \\
\hline & & & No tienen & 0 \\
\hline
\end{tabular}

Fuente: elaboración propia con base en Jiménez (2006) 


\section{Variables de contrastación}

La investigación propuesta está circunscrita bajo el paradigma positivista, el cual se puede calificar como cuantitativo, empírico-analítico, racionalista, sistemático gerencial y científico-tecnológico. Este paradigma sustenta investigaciones que tienen por objetivo determinar variables mediante una expresión numérica (Ricoy, 2006). Para medir la competitividad, el BID planteó su mapa de competitividad, donde se visualiza a la organización como un sistema integrado por ocho áreas, que, al interconectarse entre sí, mejoran su desempeño (Martínez y Álvarez, 2006); este mapa incluye variables de distinta naturaleza, que son internas a la organización y que, por lo tanto, se encuentran bajo su control; considerando que el nivel de la competitividad de las empresas depende de factores o áreas, dichas áreas son: planeamiento estratégico, cadena de valor, aseguramiento de la calidad, mercado local y nacional, contabilidad y finanzas, talento humano, gestión ambiental y sistemas de información.

El mapa de competitividad del BID planteado en la presente investigación incluye las ocho áreas de la empresa; sin embargo, el número de preguntas fue reducido de i24, que corresponde al esquema original (Montoya y Silvestre, 2008), a 63. Dicho ajuste se realizó dada la naturaleza de las organizaciones analizadas, que son de origen campesino y solidario, las cuales se diferencian de la empresa privada, en particular de una pequeña o mediana empresa, para las que fue desarrollada esta metodología en un principio.

Las respuestas de las preguntas pasaron de ser categóricas, con cinco niveles de respuesta (de ○ a 5), a ser dicotómicas, es decir, con dos niveles de respuesta (o en ausencia o incumplimiento de la característica y i si esta se cumple); cada pregunta fue ponderada de acuerdo con su nivel de importancia (tabla 3, 3a, 3b, 3c, 3d, 3e, $3 \mathrm{f}, 3 \mathrm{~g}$, $3 \mathrm{~h}$. 3i. 3j, 3k. 3l) y se realizó el análisis de fiabilidad en la parte del instrumento referente al mapa del BID, con un alfa de Cronbach de 0,945 . George y Mallery (2003) catalogan como "excelentes" los trabajos un con alfa de Cronbach superior a $\circ, 90$, lo que significa que los ítems analizados tienen una alta consistencia interna.

TABLA 3

ÍNDICE DE COMPETITIVIDAD EMPRESARIAL (ICE)

\begin{tabular}{|c|c|c|c|c|c|}
\hline Factor & Ponderación & Característica & Ponderación & Indicador & Ponderación \\
\hline \multirow{7}{*}{$\begin{array}{l}\text { Planeamiento } \\
\text { estratégico }\end{array}$} & \multirow{7}{*}{13} & \multirow{5}{*}{ Proceso } & \multirow{5}{*}{9} & $\begin{array}{l}\text { La organización ha realizado algún proceso de } \\
\text { planeamiento estratégico }\end{array}$ & 3 \\
\hline & & & & $\begin{array}{l}\text { La organización tiene una estrategia de negocios } \\
\text { escrita y conocida por todos }\end{array}$ & 1 \\
\hline & & & & $\begin{array}{l}\text { Se están dando espacios para que todos se } \\
\text { involucren en la planeación estratégica }\end{array}$ & 2 \\
\hline & & & & $\begin{array}{l}\text { El planeamiento estratégico es un resultado de } \\
\text { trabajo en equipo }\end{array}$ & 2 \\
\hline & & & & $\begin{array}{l}\text { La organización se fija objetivos cuantificables y } \\
\text { con plazos específicos }\end{array}$ & 2 \\
\hline & & \multirow{2}{*}{ Implementación } & \multirow{2}{*}{4} & $\begin{array}{l}\text { Los asociados están involucrados en el logro de los } \\
\text { objetivos de la organización }\end{array}$ & 3 \\
\hline & & & & $\begin{array}{l}\text { La planeación que se hace da las pautas para la } \\
\text { asignación de recursos }\end{array}$ & 1 \\
\hline
\end{tabular}


TABLA 3 (cont.)

ÍNDICE DE COMPETITIVIDAD EMPRESARIAL (ICE)

\begin{tabular}{|c|c|c|c|c|c|}
\hline Factor & Ponderación & Característica & Ponderación & Indicador & Ponderación \\
\hline \multirow[t]{18}{*}{$\begin{array}{l}\text { Cadena de } \\
\text { valor }\end{array}$} & \multirow[t]{18}{*}{25} & \multirow[t]{3}{*}{ Planificación } & \multirow[t]{3}{*}{4} & $\begin{array}{l}\text { Los productores tienen procesos de producción } \\
\text { adecuados }\end{array}$ & 2 \\
\hline & & & & $\begin{array}{l}\text { Las técnicas empleadas por los productores } \\
\text { permiten productos competitivos }\end{array}$ & 1 \\
\hline & & & & $\begin{array}{l}\text { Los asociados tienen máquinas que les permiten } \\
\text { obtener productos competitivos }\end{array}$ & 1 \\
\hline & & \multirow[t]{2}{*}{ Capacidad } & \multirow[t]{2}{*}{2} & $\begin{array}{l}\text { La asociación conoce la capacidad de producción } \\
\text { de sus asociados }\end{array}$ & 1 \\
\hline & & & & $\begin{array}{l}\text { La organización tiene planes para ampliar la } \\
\text { capacidad de producción de sus socios }\end{array}$ & 1 \\
\hline & & \multirow[t]{4}{*}{ Mantenimiento } & \multirow[t]{4}{*}{4} & $\begin{array}{l}\text { La organización incentiva el mantenimiento de las } \\
\text { máquinas entre sus socios }\end{array}$ & 1 \\
\hline & & & & $\begin{array}{l}\text { Los asociados hacen mantenimiento de los equipos } \\
\text { que usan para la producción }\end{array}$ & 1 \\
\hline & & & & $\begin{array}{l}\text { La organización tiene piezas y repuestos para las } \\
\text { máquinas de sus socios }\end{array}$ & 1 \\
\hline & & & & $\begin{array}{l}\text { La organización (socios) tiene seguros contra } \\
\text { calamidades que afecten el cultivo }\end{array}$ & 1 \\
\hline & & \multirow[t]{2}{*}{ Investigación y desarrollo } & \multirow[t]{2}{*}{4} & $\begin{array}{l}\text { La organización fomenta la innovación en los } \\
\text { procesos de producción }\end{array}$ & 2 \\
\hline & & & & $\begin{array}{l}\text { La organización tiene plan de mejora de semillas y } \\
\text { adquisición de nuevas máquinas }\end{array}$ & 2 \\
\hline & & \multirow[t]{3}{*}{ Aprovisionamiento } & \multirow[t]{3}{*}{3} & $\begin{array}{l}\text { Existen criterios formales para la adquisición de } \\
\text { semillas, maquinaria, etc. }\end{array}$ & 1 \\
\hline & & & & $\begin{array}{l}\text { La organización tiene programas de abastecimiento } \\
\text { de semillas e insumos }\end{array}$ & 1 \\
\hline & & & & $\begin{array}{l}\text { La organización tiene planes de contingencia para } \\
\text { obtener semillas, maquinaria, etc. }\end{array}$ & 1 \\
\hline & & \multirow[t]{2}{*}{ Manejo de inventarios } & \multirow[t]{2}{*}{4} & $\begin{array}{l}\text { Los productores tienen un inventario adecuado de } \\
\text { semillas }\end{array}$ & 2 \\
\hline & & & & $\begin{array}{l}\text { Existen mecanismos adecuados de almacenamiento } \\
\text { de los productos agrícolas }\end{array}$ & 2 \\
\hline & & \multirow[t]{2}{*}{ Ubicación de cultivos } & \multirow[t]{2}{*}{4} & $\begin{array}{l}\text { La organización impulsa programas de calidad y } \\
\text { mejores prácticas entre asociados }\end{array}$ & 3 \\
\hline & & & & $\begin{array}{l}\text { Las normas de calidad están documentadas y son } \\
\text { conocidas por los asociados }\end{array}$ & 1 \\
\hline \multirow[t]{7}{*}{$\begin{array}{l}\text { Aseguramiento } \\
\text { de calidad }\end{array}$} & \multirow[t]{7}{*}{14} & \multirow[t]{2}{*}{ Aspectos generales } & \multirow[t]{2}{*}{4} & $\begin{array}{l}\text { La organización impulsa programas de calidad y } \\
\text { mejores prácticas entre asociados }\end{array}$ & 3 \\
\hline & & & & $\begin{array}{l}\text { Las normas de calidad están documentadas y son } \\
\text { conocidas por los asociados }\end{array}$ & 1 \\
\hline & & \multirow[t]{5}{*}{ Sistema } & \multirow[t]{5}{*}{10} & $\begin{array}{l}\text { Los productos obtenidos por sus asociados son de } \\
\text { calidad }\end{array}$ & 3 \\
\hline & & & & $\begin{array}{l}\text { Se han producido mejoras en la calidad de los } \\
\text { productos obtenidos }\end{array}$ & 2 \\
\hline & & & & $\begin{array}{l}\text { Se hace control en los cultivos y se implementan } \\
\text { medidas correctivas }\end{array}$ & 2 \\
\hline & & & & $\begin{array}{l}\text { En el proceso de selección de semillas se hacen } \\
\text { procesos de control de calidad }\end{array}$ & 2 \\
\hline & & & & $\begin{array}{l}\text { La asociación documenta los procesos de control de } \\
\text { calidad }\end{array}$ & 1 \\
\hline \multirow{5}{*}{$\begin{array}{l}\text { Mercadeo: } \\
\text { local y nacional }\end{array}$} & \multirow{5}{*}{8} & \multirow{4}{*}{ Mercados y ventas } & \multirow{4}{*}{7} & $\begin{array}{l}\text { La organización realiza directamente la } \\
\text { comercialización de sus productos }\end{array}$ & 3 \\
\hline & & & & $\begin{array}{l}\text { La organización conoce al cliente e interactúa con } \\
\text { este }\end{array}$ & 2 \\
\hline & & & & $\begin{array}{l}\text { La organización conoce a otras asociaciones que } \\
\text { produzcan este mismo producto }\end{array}$ & 1 \\
\hline & & & & $\begin{array}{l}\text { La organización (socios) puede fijar el precio de } \\
\text { venta del producto }\end{array}$ & 1 \\
\hline & & Distribución & 1 & $\begin{array}{l}\text { La organización (asociados) tiene un sistema de } \\
\text { distribución de sus productos }\end{array}$ & 1 \\
\hline
\end{tabular}


TABLA 3 (cont.)

ÍNDICE DE COMPETITIVIDAD EMPRESARIAL (ICE)

\begin{tabular}{|c|c|c|c|c|c|}
\hline Factor & Ponderación & Característica & Ponderación & Indicador & Ponderación \\
\hline \multirow{7}{*}{$\begin{array}{l}\text { Contabilidad y } \\
\text { finanzas }\end{array}$} & \multirow{7}{*}{11} & \multirow{3}{*}{ Monitoreo de costos y contabilidad } & \multirow{3}{*}{5} & $\begin{array}{l}\text { La contabilidad de la organización genera } \\
\text { información para la toma de decisiones }\end{array}$ & 1 \\
\hline & & & & $\begin{array}{l}\text { La junta directiva recibe informes periódicos de los } \\
\text { registros contables }\end{array}$ & 2 \\
\hline & & & & $\begin{array}{l}\text { La asamblea general recibe información de los } \\
\text { registros contables }\end{array}$ & 2 \\
\hline & & \multirow{4}{*}{ Administración financiera } & \multirow{4}{*}{6} & $\begin{array}{l}\text { La organización hace procesos de planificación } \\
\text { financiera }\end{array}$ & 2 \\
\hline & & & & $\begin{array}{l}\text { La organización conoce los costos e ingresos que } \\
\text { obtienen sus asociados }\end{array}$ & 2 \\
\hline & & & & $\begin{array}{l}\text { La organización tiene cuantificado financieramente } \\
\text { el valor de sus activos }\end{array}$ & 1 \\
\hline & & & & $\begin{array}{l}\text { La organización conoce los márgenes de utilidad de } \\
\text { sus socios }\end{array}$ & 1 \\
\hline \multirow{10}{*}{$\begin{array}{l}\text { Talento } \\
\text { humano }\end{array}$} & \multirow{10}{*}{20} & \multirow{4}{*}{ Aspectos generales } & \multirow[t]{4}{*}{4} & La organización tiene manual de funciones escritos & 1 \\
\hline & & & & $\begin{array}{l}\text { La organización tiene manuales de procedimientos } \\
\text { escritos }\end{array}$ & 1 \\
\hline & & & & Existe una junta directiva que lidera la organización & 1 \\
\hline & & & & La organización tiene un administrador o gerente & 1 \\
\hline & & Capacitación de los asociados & 3 & $\begin{array}{l}\text { La organización tiene un programa de capacitación } \\
\text { establecido para sus socios }\end{array}$ & 3 \\
\hline & & \multirow{4}{*}{ Cultura organizacional } & \multirow[t]{4}{*}{11} & Existe una buena comunicación en la organización & 3 \\
\hline & & & & Los asociados tienen sentido de pertenencia & 3 \\
\hline & & & & Se estimula el trabajo en equipo & 2 \\
\hline & & & & $\begin{array}{l}\text { La organización ha establecido programas para } \\
\text { mejorar la convivencia }\end{array}$ & 3 \\
\hline & & Salud y seguridad laboral & 2 & $\begin{array}{l}\text { La organización presta servicios de seguridad social } \\
\text { a sus socios }\end{array}$ & 2 \\
\hline \multirow{2}{*}{$\begin{array}{l}\text { Gestión } \\
\text { ambiental }\end{array}$} & \multirow{2}{*}{2} & \multirow{2}{*}{ Concientización y capacitación } & \multirow[t]{2}{*}{2} & $\begin{array}{l}\text { La organización promueve el cuidado del medio } \\
\text { ambiente entre sus socios }\end{array}$ & 1 \\
\hline & & & & $\begin{array}{l}\text { La organización implementa charlas o talleres para } \\
\text { el cuidado ambiental }\end{array}$ & 1 \\
\hline \multirow{7}{*}{$\begin{array}{l}\text { Sistema de } \\
\text { información }\end{array}$} & \multirow{7}{*}{7} & \multirow{2}{*}{ Planeación } & \multirow[t]{2}{*}{2} & $\begin{array}{l}\text { La organización tiene sistema de información } \\
\text { interno externo }\end{array}$ & 1 \\
\hline & & & & La organización usa recursos informáticos & 1 \\
\hline & & Entradas & 1 & $\begin{array}{l}\text { En la organización se archivan en medio magnético } \\
\text { los documentos importantes }\end{array}$ & 1 \\
\hline & & Procesos & 1 & $\begin{array}{l}\text { La organización realiza copia de respaldo de } \\
\text { archivos }\end{array}$ & 1 \\
\hline & & \multirow{3}{*}{ Salidas } & \multirow[t]{3}{*}{3} & $\begin{array}{l}\text { La información que se genera en medio magnético } \\
\text { es clara y oportuna }\end{array}$ & 1 \\
\hline & & & & $\begin{array}{l}\text { Los datos que se generan sirven para la toma de } \\
\text { decisiones }\end{array}$ & 1 \\
\hline & & & & Se emplean hojas de cálculo, se hacen gráficas, etc. & 1 \\
\hline Total & 100 & Total & 100 & Total & 100 \\
\hline
\end{tabular}

Fuente: elaboración propia con base en Montoya y Silvestre (2008) y Castaño y Gutiérrez (20II) 


\section{Índice de capacidad organizacional (ICO) e índice de competitividad empresarial (ICE)}

En lo que respecta a la manera de calcular índices, ya sea de competitividad o de capacidad organizacional, dado su carácter multidimensional, se han planteado indicadores compuestos, es decir, indicadores que combinan más de una magnitud a la vez o que expresan de manera resumida la variación promedio de un conjunto de variables (Alonso, 2004). El índice o la magnitud que se obtiene se constituye desde el agregado de indicadores simples, que se logran al ponderar estos con unos pesos, que representan la importancia relativa de cada uno de ellos dentro del indicador agregado.

Para el abordaje de la presente investigación y desde el enfoque del BID (citado en Montoya y Silvestre, 2008), se construye un índice sintético basado en el más simple de los métodos de agregación y de ponderación: la agregación simple y una ponderación ad hoc a criterio del investigador. En este caso, se escogieron 8 factores, con ponderaciones que oscilan entre los 2 y 25 puntos; 24 variables, con ponderaciones entre i y i puntos, y, finalmente, se tuvieron en cuenta 63 indicadores, ponderados de i a 3 puntos. Estos indicadores tienen como respuesta la opción sí, que indica presencia de un aspecto, y no, que indica su ausencia; el objetivo es que se obtenga la mayor cantidad de respuestas afirmativas, para lograr un resultado alto, de 100, o muy cercano a este.

Por otro lado, el caso del ICO presenta 5 temas, 15 categorías y 43 indicadores, cuyas opciones de respuesta, que son categóricas, están calificadas de $\circ$ a 7 ; el puntaje mayor de este indicador es de 100 , pero se considera aceptable un nivel de 70 puntos en las organizaciones. Una vez ponderadas las variables tanto en el ICO como en el ICE, los dos indicadores se obtienen desde una agregación simple (Domínguez, Blancas, Guerrero y González, 20II); el indicador para una unidad i se define así:

$$
\begin{gathered}
I S_{i}=w \cdot I_{i 1}+w \cdot I_{i 2}+\cdots+w \cdot I_{i m}=\sum_{j=1}^{m} w \cdot I_{i j} \\
I C O_{i}=\sum_{j=1}^{m} w \cdot I_{i j} \\
I C E_{j}=\sum_{i=1}^{m} w \cdot I_{i j}
\end{gathered}
$$

Así, w representa el peso otorgado a los indicadores, e $\mathrm{I}_{\mathrm{ij}}$, el valor del indicador j para la unidad i. Los valores de los indicadores hallados van de o puntos (la cifra más baja, o la peor) hasta ioo (la cifra más alta, o la mejor); que una organización tenga un ICO cercano a roo puntos indica que dicha organización tiene mayor capacidad para contratar y gestionar proyectos, lo que garantiza de alguna forma su permanencia en el futuro. Por otro lado, para el caso del ICE, organizaciones con un mayor puntaje, es decir, más cercano a Ioo, son organizaciones más competitivas. Se esperaría, así, una relación directa o positiva entre ambos indicadores, es decir, que asociaciones mejor organizadas sean más competitivas.

Finalmente, la competitividad de las organizaciones fue categorizada en cuatro niveles, de acuerdo con la propuesta metodológica de la Universidad Manuela Beltrán, de Colombia: nivel de competitividad bajo, nivel de competitividad medio-bajo, nivel de competitividad medio-alto y nivel de competitividad alto (Jiménez, 2006) (tabla 4$)$. 
TABLA 4

NivELES DE COMPETITIVIDAD EMPRESARIAL

\begin{tabular}{cc}
\hline Nivel de competitividad & Puntaje del indicador (ICE) en puntos \\
\hline Alto: muy competitiva & $100-90$ \\
\hline Medio-alto: competitiva & $89-80$ \\
\hline Medio-bajo: poco competitiva & $79-70$ \\
\hline Bajo: no es competitiva & $69-0$ \\
\hline
\end{tabular}

Fuente: elaboración propia con base en Jiménez (2006)

Se dice que una organización con puntaje menor a 69 puntos (base de roo puntos) tiene problemas en las distintas áreas que fueron medidas, pues su demanda y oferta es estacional, depende del mercado local y cuenta con nulas posibilidades de insertarse en el mercado internacional. Estas organizaciones tenderán a desaparecer completamente ante cualquier cambio en el contexto que posibilite la entrada de sustitutos de otros países a los mercados donde operan.

Una organización con puntaje de 70 a 79 puntos (base de 100 puntos) es una organización que tiene algunos elementos que le han permitido sobrevivir en el mercado local, pero que definitivamente no tiene las condiciones necesarias para insertarse en el mercado internacional y su supervivencia estará supeditada a que las condiciones locales permanezcan como están, lo cual es imposible dadas las tendencias de globalización.

Por otra parte, las organizaciones con puntaje de 80 a 89 puntos (base de 100 puntos) son organizaciones que mantienen elementos diferenciadores, una estructura de costos y un sistema de calidad adecuada que le han permitido mantenerse en el mercado local y que podrán ingresar a los mercados internacionales en un tiempo relativamente corto.

Finalmente, las organizaciones con puntaje de 90 a 100 puntos (base de 100 puntos) tienen niveles altos de competitividad, son maduras, adaptables, flexibles y totalmente internacionalizadas y están en la búsqueda constante de innovaciones que les permitan mantenerse en el mercado internacional.

\section{Resultados}

La producción de aguacate en Sucre se ha ido incrementando entre 2007 y 2015 (figura I) y está soportada por una cadena de valor que tiene varios eslabones (figura 2), de los cuales el más importante es el de los productores. Estos se asociaron en una serie de organizaciones que surgieron con el objetivo central, desde el cooperativismo, de mejorar las condiciones económicas de sus asociados y de sus familias, a partir del logro de mejores términos en materia de comercialización de y acceso a recursos financieros y técnicos y materias primas. 


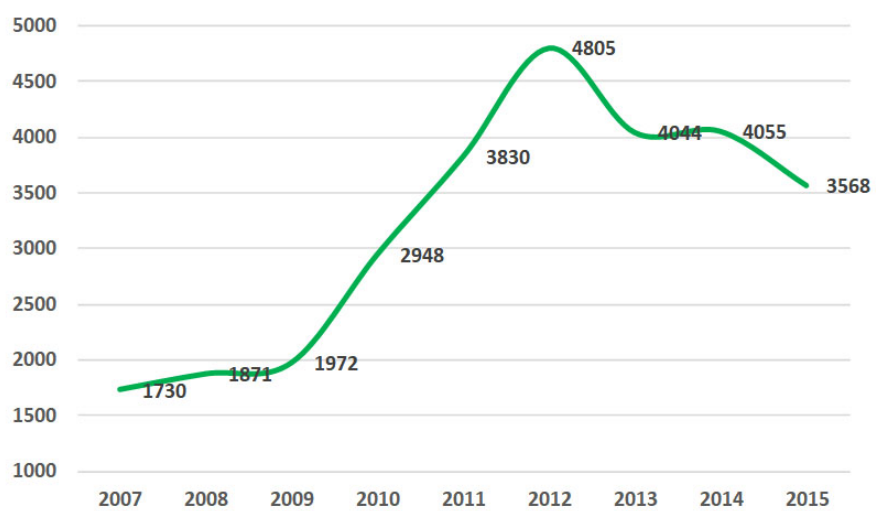

FIGURA 1

SUCRE: PRODUCCIÓN DE AGUACATE EN LOS AÑos 2007-2015

Fuente: Agronet (s. F.)

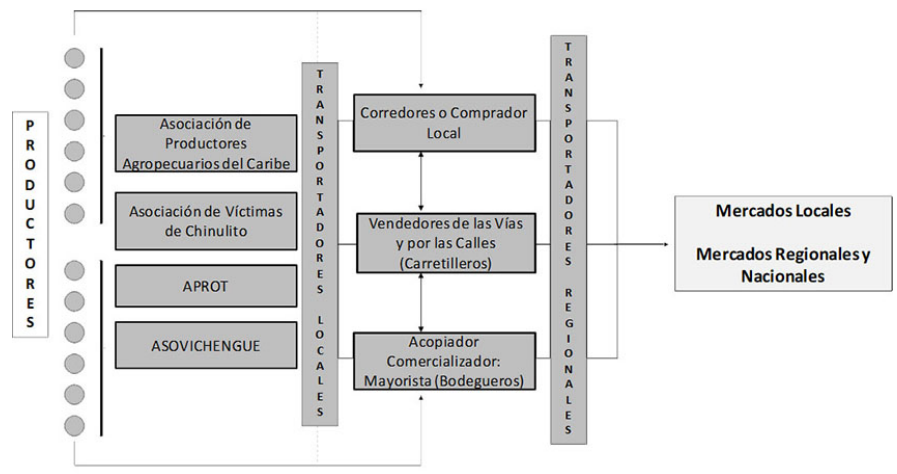

FIGURA 2.

Cadena de valor del aguacate

Fuente: elaboración propia con base en Corporación para el Desarrollo Participativo

y Sostenible y de los Pequeños Productores Rurales (Cor poración PBA) (2011)

Las organizaciones de productores de aguacate en Sucre son cuatro: dos, en Ovejas; una, en Chalán, y una, en Colosó; todas estas se dedican a producir y comercializar bienes agropecuarios y tienen entre 29 y 250 asociados (figura 3).

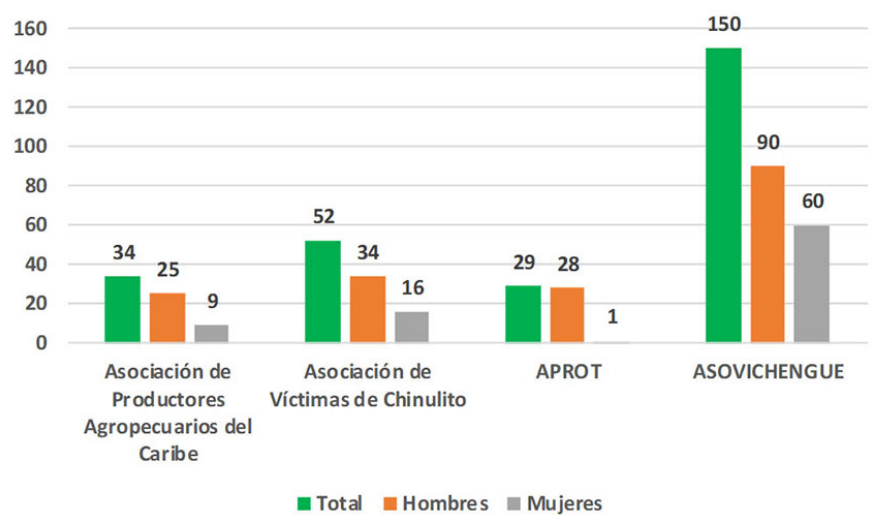

FIGURA 3

Sucre: número de asociados de las organizaciones productoras de aguacate en 2017 Fuente: elaboración propia 
Machado (2000) afirma que el papel de las organizaciones en el sector rural no se limita a servir de base para el desarrollo del capital social, sino que también cumplen otras funciones, como facilitar la ejecución de proyectos, servir de instrumento de relacionamiento entre lo público y lo privado, reunir y transmitir conocimiento, defender los intereses de la comunidad, prestar servicios a sus miembros, participar en emprendimientos innovadores y asumir, en determinadas circunstancias, el suministro de bienes públicos a través de contratos con el Estado, entre otras. Podrá decirse que sin organización es difícil alcanzar el desarrollo del país.

De las organizaciones campesinas indagadas, el $75 \%$ están legalmente constituidas, con personería jurídica desde el año 2000. A nivel organizacional, estas asociaciones tienen una estructura piramidal (figura 4), en la que el representante legal es la cabeza; luego está la junta administradora (conformada generalmente por presidente, vicepresidente, secretario, tesorero, fiscal y vocales), y, finalmente, los asociados. Típicamente, en este tipo de organizaciones, el poder de decisión y de acción está en manos de los asociados, quienes actúan en consenso, mientras que los demás niveles están supeditados a este órgano. Cabe destacar que, en la mitad de las organizaciones indagadas, los asociados están organizados en comités que operativizan las acciones. En particular, en la tabla 5 se muestran los resultados más importantes, a nivel descriptivo, de las organizaciones productoras de aguacate en Sucre.

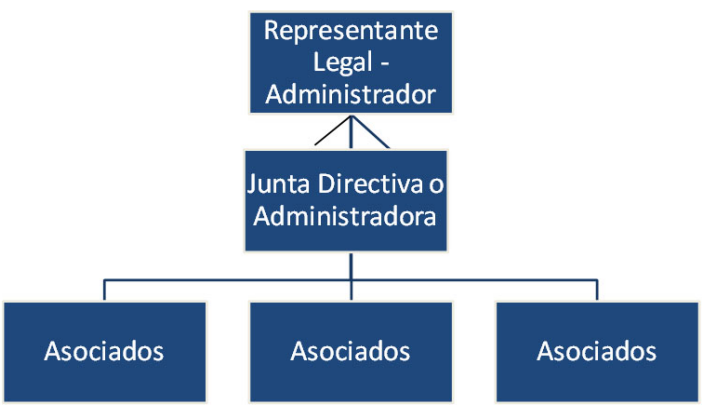

FIGURA 4

SuCre: ORgAnigrama de las ASOciaciones PRODUCTORAS DE AGUACATE

FUENTE: ELABORACIÓN PROPIA

TABLA 5

Sucre: Características de las ASOciaciones PRoductoras de AGUACATE EN 2017

\begin{tabular}{|c|c|}
\hline Aspecto & Descripción \\
\hline $\begin{array}{l}\text { Registros escritos: actas de } \\
\text { reuniones }\end{array}$ & $\begin{array}{l}\text { Las organizaciones de productores levan registros escritos de sus reuniones en actas, y además llevan libros contables; } \\
\text { en el } 75 \% \text { de los casos se tienen planes de acción, y en la mitad de los casos se implementa un sistema de evaluación } \\
\text { de gestión. }\end{array}$ \\
\hline Manejo de productos financieros & $\begin{array}{l}\text { Las organizaciones de productores de aguacate en Sucre manejan productos financieros, como cuentas de ahorro y } \\
\text { corrientes. La mayoría de las organizaciones no gestionan proyectos con fuentes externas. }\end{array}$ \\
\hline $\begin{array}{l}\text { Alianzas y relaciones con otras } \\
\text { organizaciones }\end{array}$ & $\begin{array}{l}\text { En el } 75 \% \text { de los casos, sí existen alianzas, principalmente en acciones de asesoría y capacitación, el desarrollo de } \\
\text { proyectos en conjunto y en el tema de reparación a las víctimas del conflicto armado interno. Por otro lado, la mitad } \\
\text { de las organizaciones tiene relaciones con las administraciones locales para la gestión de proyectos, coordinación de } \\
\text { mesas de víctimas y capacitación; sin embargo, con estas entidades nunca han tenido ningún tipo de relación } \\
\text { contractual. }\end{array}$ \\
\hline Tenencia de activos & $\begin{array}{l}\text { En cuanto a los activos de los que disponen las organizaciones productoras de aguacate en Sucre, aunque en el } 75 \% \\
\text { de los casos se tiene un lugar propio para operar, solo en el } 25 \% \text { de los casos este lugar está equipado con muebles, } \\
\text { enseres y equipos de oficina adecuados para el funcionamiento de la organización. }\end{array}$ \\
\hline Capital de trabajo & $\begin{array}{l}\text { Solo en la mitad de los casos, las organizaciones cuentan con este recurso, el cual proviene de una fuente de } \\
\text { financiación externa. }\end{array}$ \\
\hline Beneficios para los asociados & $\begin{array}{l}\text { La mitad de las organizaciones ofrecen a sus asociados y sus familias algunos servicios, como microcréditos — cuyo } \\
\text { monto no supera un salario mínimo legal vigente-, la asistencia técnica en el manejo de semillas, estudio de suelos, } \\
\text { viveros, distribución de plántulas, control de calidad de los productos, etc.; sin embargo, las organizaciones no tienen } \\
\text { programas para grupos particulares de la población, tales como niños, mujeres o jóvenes, salvo algún programa de } \\
\text { capacitación que han recibido de algunas entidades no gubernamentales. }\end{array}$ \\
\hline
\end{tabular}

Fuente: elaboración propia 


\section{Capacidad organizacional}

La capacidad organizacional de las asociaciones fue estimada a través del ICO, el cual tuvo un resultado relativamente bajo para la mayoría de estas organizaciones, por debajo de 70 puntos en el $75 \%$ de los casos; en promedio, el nivel de capacidad organizacional para las productoras de aguacate fue de 52,75 puntos, lo que equivale a un porcentaje de cumplimiento del $54,40 \%$ del total de temas. Cabe destacar que las organizaciones que tienen residencia en el municipio de Ovejas son las que están en el nivel más bajo, pues su indicador no superó los 40 puntos (figura 5).

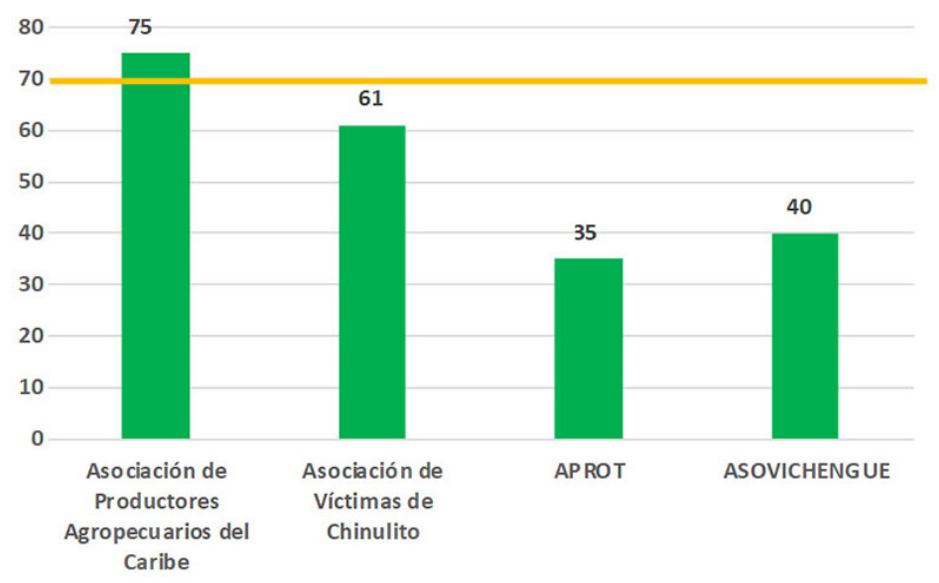

FIGURA 5

SuCRE: ÍNDICE DE CAPACIDAD ORGANIZACIONAL (ICO) DE LAS ORGANIZACIONES PRODUCTORAS DE AGUACATE EN 2017

FUENTE: ELABORACIÓN PROPIA

Las principales debilidades de las organizaciones productoras de aguacate en Sucre se enfocan en aspectos como la situación económica, dado que estas asociaciones adolecen de activos propios para desarrollar su objeto social; otra debilidad son los servicios ofrecidos a sus integrantes, debido a que estas agremiaciones prácticamente no tienen programas de apoyo a sus asociados y familias.

Otra debilidad presente en las organizaciones, a excepción de la Asociación de Productores Agropecuarios del Caribe, es el tema de la capacidad gerencial (figura 6), toda vez que en el $75 \%$ de los casos no tienen plan de acción, mecanismos de evaluación de gestión ni órganos internos de control y que no hacen gestión para conseguir proyectos, tanto con entidades públicas como privadas.

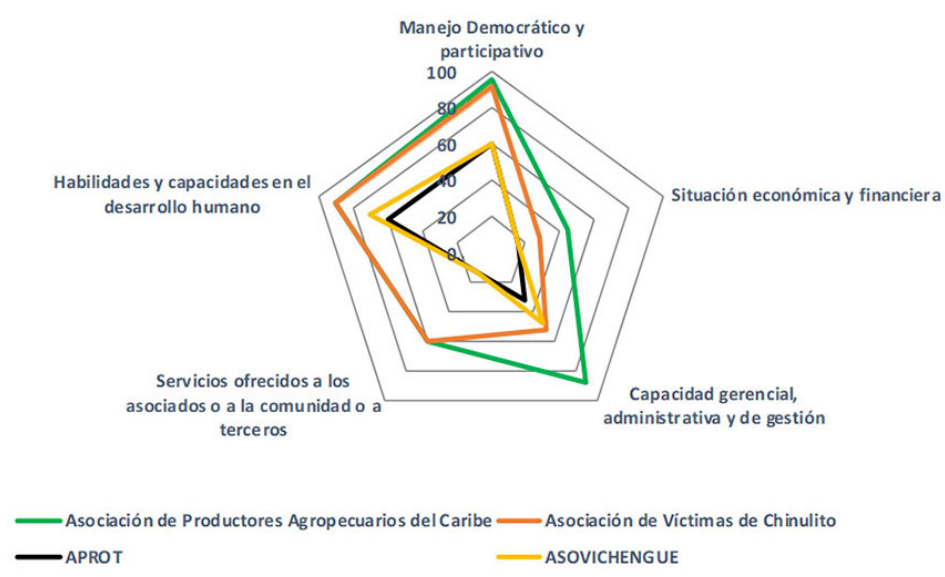

FIGURA 6

Sucre: temas del índice de capacidad organizacional (ICO) de las organizaciones productoras de aguacate en 2017 Fuente: elaboración propia 
En cuanto a las fortalezas, el manejo democrático y participativo de sus asociados y las habilidades y capacidades en el desarrollo humano son importantes (figura 6); con relación a estos aspectos, existen realidades que son comunes a los campesinos de estos municipios, ligadas a los procesos de violencia de la zona; en este sentido, las organizaciones campesinas son una forma de reconstruir tejido social y de recuperar el capital social en lugares donde la violencia ha estado presente.

Dado que una de las deficiencias serias que tienen los países para el desarrollo rural es el capital social, en relación con otros capitales, las organizaciones están llamadas a desempeñar un papel significativo en ofrecer una base para el desarrollo de ese capital. Ello, porque las interacciones entre agentes se facilitan enormemente cuando estos hacen parte de una organización legitimada y reconocida en su medio (Machado, 2000).

\section{Competitividad empresarial}

Además del tema de capacidad organizacional, está el tópico de la competitividad, vista como una capacidad. De acuerdo con los resultados obtenidos, dos de las organizaciones, en particular las que están ubicadas en el municipio de Ovejas, no son competitivas, pues obtuvieron puntajes inferiores a 69 puntos; son organizaciones cuya demanda y oferta es estacional y depende del mercado local, con nulas posibilidades de insertarse en el mercado internacional. Por otro lado, las otras dos organizaciones, la de Colosó y la de Chalán, tienen baja competitividad, pues su puntaje está entre 70 y 79 puntos; es decir, son organizaciones que tienen algunos elementos que les han permitido sobrevivir en el mercado local, pero definitivamente no tienen las condiciones necesarias para insertarse en el mercado internacional (figura 7). En promedio, el nivel de competitividad de estas asociaciones fue de 57,75 puntos, lo que equivale a un nivel de cumplimiento de los factores del 55,53\%.

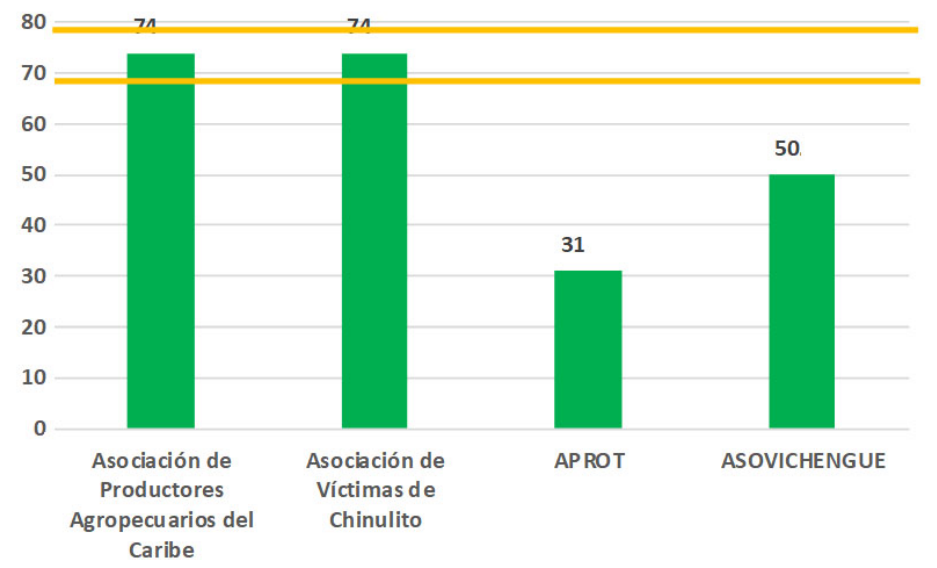

FIGURA 7

SuCRE: ÍNDICE DE COMPETITIVIDAD EMPRESARIAL (ICE) DE LAS ORGANIZACIONES PRODUCTORAS DE AGUACATE EN 2017 FuENTE: ELABORACIÓN PROPIA

Entre las principales debilidades que tienen estas organizaciones están las siguientes: escasa consolidación de su cadena de valor, regular manejo de su contabilidad y finanzas, la disponibilidad, formación y valoración del recurso humano, escasa gestión ambiental y falta de sistemas de información adecuados; por otro lado, entre las fortalezas se pueden destacar el eficiente planeamiento estratégico y la gestión de la calidad, al menos en el 50\% de las organizaciones indagadas (figura 8). De las debilidades presentadas, la consolidación de la cadena de valor es una de las más difíciles de salvar. La cadena de valor está conformada por una serie de etapas de agregación de valía en los procesos productivos (Francés, 200I), y la explotación del aguacate en Sucre carece de cualquier proceso de transformación productiva. 

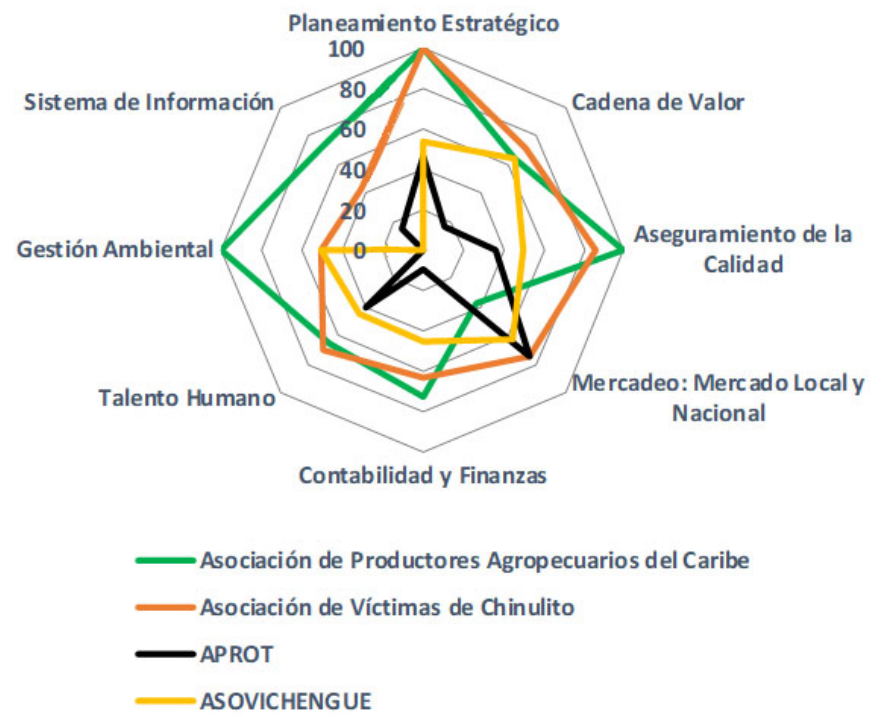

FIGURA 8

SuCRE: FACTORES DEL ÍNDICE DE COMPETITIVIDAD EMPRESARIAL (ICE) DE LAS ORgANiZACIONES PRODUCTORAS DE AGUACATE EN 2017 FUENTE: ELABORACIÓN PROPIA

\section{Discusión}

Las organizaciones productoras de aguacate en Sucre no son competitivas, no solo por sus condiciones organizacionales internas, sino por las condiciones del contexto -competitividad macro- y del producto que generan. Esto contrasta con lo que comenta Thurow (1985, quien menciona que la competitividad es un problema de posicionamiento de las empresas en los mercados internacionales y no del crecimiento de la productividad. Por otra parte, a nivel micro, los bajos niveles de competitividad se deben a condiciones organizacionales y propias de la competitividad. Las principales debilidades encontradas desde la perspectiva de la organización interna son las que a continuación se describen: a la débil situación económica de los productores de la región; b escasos beneficios y servicios para los asociados y sus familias, derivados de la venta del aguacate a la sociedad en la región; c la baja capacidad gerencial de los líderes y representantes de las organizaciones económicas de los productores, y del escaso poder de gestión de proyectos por parte de las organizaciones de productores. Lo anterior fue descrito por Tamames (1988, quien menciona que la competitividad es la habilidad sostenible de las empresas para obtener ganancias y mantener la participación en el mercado.

A nivel competitivo, las principales debilidades están relacionadas con la baja consolidación de la cadena de valor, el deficiente manejo contable y financiero, la escasa disponibilidad de formación de las organizaciones y la valoración del recurso humano y la inadecuada gestión ambiental. Esto ha sido descrito también por Haguenauer (1990), quien menciona que la competitividad es la capacidad de una industria o empresa para producir bienes con patrones de calidad específicos, utilizando más eficientemente los recursos que otras empresas o industrias semejantes en el resto del mundo durante un cierto periodo de tiempo; también Landau (199i) relaciona la competitividad con la habilidad de proveer una tasa aceptable de crecimiento y un estándar de vida sostenido para sus ciudadanos, mientras que eficientemente se provee empleo sin reducir el crecimiento potencial y estándar de vida de las futuras generaciones. 
Existe una fuerte correlación entre la capacidad organizacional que tienen las asociaciones campesinas y la competitividad de estas; organizaciones fortalecidas a nivel interno, que tengan mayor capacidad de gestión, serán organizaciones con mejores niveles de competitividad. En el caso de las asociaciones indagadas, estas presentan debilidades a nivel organizacional y, por ende, bajos niveles de competitividad. Bianco (2007) ya ha reportado esta información cuando menciona que la competitividad desde el enfoque macroeconómico es la capacidad de las economías nacionales para lograr ciertos resultados, y en algunos casos resultados más amplios, como el mejoramiento del nivel de vida y mayor bienestar social; por otro lado, la competitividad desde el enfoque microeconómico es la capacidad para planear, producir y vender un producto ventajosamente frente a los competidores (figura 9).

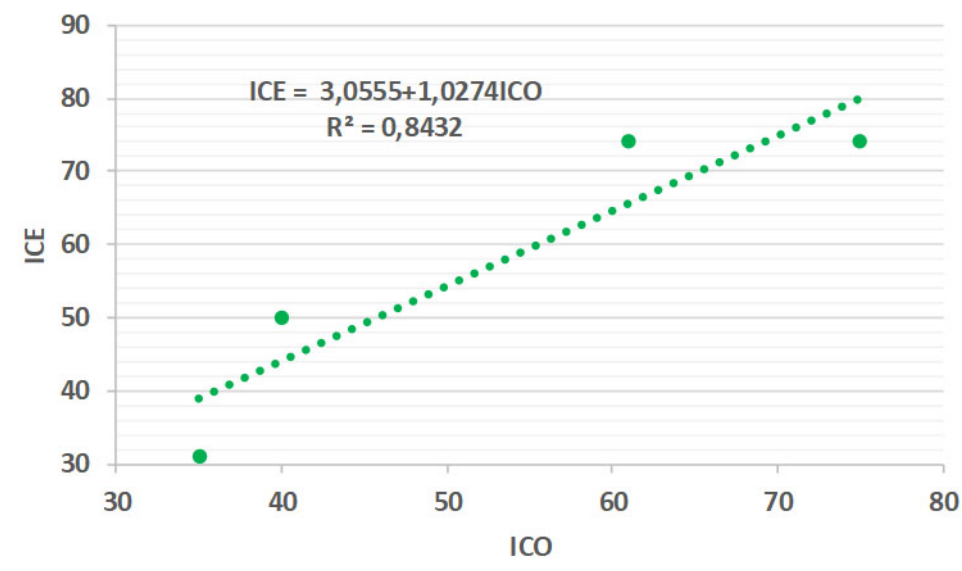

FIGURA 9

Sucre: correlación entre el índice de capacidad organizacional (ICO) y el índice de competitividad empresarial (ICE) de las organizaciones productoras de aguacate en 2017

Fuente: elaboración propia

\section{Conclusiones}

Las organizaciones de productores de aguacate durante la cosecha no aplican adecuados sistemas de recolección, debido a la altura de los árboles y a que el fruto tiene una vida corta de anaquel, derivada de la ausencia total de una cadena de frío que promueva las condiciones aptas para su conservación en el punto de venta. El producto tiene poco o ningún valor agregado, los que en los mercados internacionales no goza de aceptación. Vale decir que, a nivel internacional, la variedad Hass es la más popular en el mercado, mientras que los productores del departamento de Sucre producen aguacate criollo de la variedad Antillana.

A partir de lo antes mencionado, la conclusión principal es que la producción de aguacate es de subsistencia y genera márgenes de rentabilidad bajos para los campesinos. 
A pesar de lo anterior, existen puntos a favor; desde el punto de vista organizacional, el manejo democrático es adecuado, la toma de decisiones es participativa y se impulsa el logro de habilidades y capacidades de desarrollo humano por parte de los asociados. En otras asociaciones indagadas, existe planeamiento estratégico, aseguramiento de la calidad y acceso a mercados locales. A partir de los hallazgos en este trabajo, la propuesta hacia las organizaciones es que deben fortalecerse a nivel interno, desde una integración estratégica en todas sus áreas, y construir un proyecto desde una planeación constante. Además, la unión entre campesinos organizados y distintas instituciones es muy necesaria, tanto para la gestión de proyectos como para el cultivo adecuado del aguacate, no solo en la fase de cultivo, sino en su transformación, a partir de la agregación de valor y en el tema de comercialización.

El fortalecimiento de la integración de la organización permite un mayor poder de decisión y control sobre las condiciones del mercado, lo que podría acortar la cadena de comercialización -reducción de intermediarios- y, así, hacer más estrecha la relación entre las organizaciones y los demandantes. Mientras tanto, a nivel del cultivo, se requiere generar formas de transformación productiva y agregación de valor, que generen nuevos productos o subproductos que sí puedan constituir una oportunidad de negocio en el mercado internacional. Para consolidar todo lo mencionado, la participación de la tríada universidad-Gobierno-empresa es fundamental.

La universidad y los centros de investigación pueden desarrollar proyectos de mejora de variedades, aplicación de técnicas agroecológicas para el tratamiento de los cultivos, manejo integral de patógenos y control de calidad en el proceso de cosecha y poscosecha. El Gobierno debe promover la creación de externalidades positivas, desde la provisión de bienes públicos, como infraestructura y carreteras, así como una política de acceso al crédito, recursos financieros, tierras, insumos y maquinaria para los campesinos.

Finalmente, la fase de comercialización puede participar en la aplicación de precios de garantía. Los precios de garantía, al menos en el corto plazo, garantizarían una rentabilidad adecuada de un negocio naciente. Todo lo anterior solo es posible en la medida en que se visione el aguacate como un cultivo promisorio, generador de ventajas competitivas para la zona y fuente de desarrollo local.

\section{Referencias}

Abdel, G., y Romo, D. (2005). Sobre el concepto de competitividad. Comercio Exterior, 55(3), 200-214. Recuperado de http://revistas.bancomext.gob.mx/rce/magazines/76/r/RCE.pdf

Agronet (s. f.). Estadísticas-Participación departamental en la producción. [Términos de búsqueda: Departamento: Sucre]. Agronet, Minagricultura. Recuperado de http://www.agronet.gov.co/estadistica/Paginas/default.a spx

Agronet. (2017). Red de información y comunicación del sector agropecuario colombiano. Documento consultado en: http://www.agronet.gov.co/Paginas/default.aspx.

Alonso, J. C. (2004). Números Índices (4.a ed.). Apuntes de Economía, (4). Recuperado de http://www.icesi.edu .co/departamentos/economia/publicaciones/docs/Apecon4.pdf

Bastidas, O. (2005). Especificidad cooperativa canadiense (r.a ed.). Caracas: Asociación Venezolana de Estudios Canadienses.

Bejarano, J. A. (1995). La competitividad en el sector agropecuario. Cuadernos de Desarrollo Agrícola, I(I), 46-56.

Bianco, C. (2007). ¿De qué hablamos cuando hablamos de competitividad? (documento de Trabajo n.o 3I). Argentina: Centro de Estudios sobre Ciencia, Desarrollo y Educación Superior. Recuperado de http://D:/Documents/Trabajo/Editorial\%20PUJ/Cuadernos\%20de\%20Desarrollo\%20Rural/Ram\%C 3\%ADrez\%20et\%20al/II27670795.EI25_Bianco_Competitividad_2007.pdf 
Brue, S. L., y Grant, R. R. (2009). Historia del pensamiento económico (7.a ed.). Ciudad de México: Cengage Learning. Recuperado de https://epulahistoria.files.wordpress.com/2016/10/stanley-brue-2009-historia-delpensamiento-economico.pdf

Cabrera, A., López, P., y Ramírez, C. (20II). La competitividad empresarial: un marco conceptual para su estudio. Universidad Central (documentos de investigación: Administración de Empresas, n.o 4). Bogotá: Universidad Central. Recuperado de https://www.ucentral.edu.co/images/documentos/editorial/2015_com petitividad_empresarial_oor.pdf

Castaño, L., y Gutiérrez, A. (20II). Propuesta para determinar la competitividad en las empresas del sector comercial del Área Metropolitana Centro Occidente (AMCO) (Tesis de grado inédita en Ingeniería Industrial). Universidad Tecnológica de Pereira, Pereira. Recuperado de http://repositorio.utp.edu.co/dspa ce/bitstream/11059/2041/1/658406C346.pdf

Chaves, R., Monzón, J. L., y Sajardo, A. (2003). Elementos de economía social. Valencia: Universidad de Valencia.

Consejo Privado de Competitividad [CPC], y Centro de Pensamiento en Estrategias Competitivas de la Universidad del Rosario [Cepec]. (2013). Índice Departamental de Competitividad. Bogotá: autores.

Corporación para el Desarrollo Participativo y Sostenible y de los Pequeños Productores Rurales (Corporación PBA). (20II). Análisis de las cadenas productivas promisorias de aguacate, ají, cacao, mango, yuca, ñame y plátano, en los municipios de San Onofre y Ovejas, en el departamento de Sucre, y El Carmen de Bolívar y San Jacinto, en el departamento de Bolívar. Estudio de caso: cadena de valor del aguacate. Bogotá: Corporación PBA, Estrategia Colombia Responde.

Dávila, C. (comp.). (2003). Empresas y empresarios en la historia de Colombia: siglos XIX y XX, una colección de estudios recientes. Bogotá: Norma, Uniandes.

Domínguez, M., Blancas, F., Guerrero, F., y González, M. (20II). Una revisión crítica para la construcción de indicadores sintéticos. Revista de Métodos Cuantitativos para la Economía y la Empresa, II, 4I-70.

Escribano, G. (1999). La interacción entre política económica y política exterior en la Unión Europea. En las III Jornadas de Política Económica "Los nuevos retos de la política económica”. Conferencia llevada a cabo por el Departamento de Economía Aplicada y Política Económica de la Universidad de Alicante.

Francés, A. (200I). Estrategias para la empresa en América Latina. Caracas: IESA.

George, D., y Mallery, P. (2003). SPSS for Windows step by step: A simple guide and reference (4.a ed.). Boston: Allyn \& Bacon.

Haguenauer, J. (1990). La competitividad: una reseña bibliográfica con énfasis en el caso brasileño. Pensamiento Iberoamericano, Sociedad Estatal Quinto Centenario, (17).

Jiménez, M. H. (2006). Modelo de competitividad empresarial. Umbral Científico, (9), II5-125.

Landau, R. (1991). How competitiveness can be achieved: Fostering economic growth and productivity. En National Academy of Engineering, Technology \& economics (pp. 3-46). Washington: The National Academy Press.

Machado, A. (2000). El papel de las organizaciones en el desarrollo rural. Bogotá: Pontificia Universidad Javeriana. Recuperado de: http://conectarural.org/sitio/reconociendo/pdf/ı-PapelOrganizaciones.pdf

Martínez, J., y Álvarez, C. (2006). Mapa de competitividad para el diagnóstico de pymes. En el XI Foro de Investigación. Foro organizado por el Congreso Internacional de Contaduría, Administración e Informática, Ciudad de México.

McFetridge, D. G. (1995). Competitiveness: Concepts and measures. Carleton University, Occasional Paper n.o 5. Montoya, L. M., y Silvestre, J. E. (2008). Aplicación del mapa de competitividad del BID a empresas del fondo 
Emprender (Tesis inédita de pregrado). Universidad Tecnológica de Pereira, Pereira. Recuperado de http:// repositorio.utp.edu.co/dspace/bitstream/handle/I1059/909/6584M798.pdf?sequence=I\&isAllowed=y.

Monzón, J. L. (2003). El cooperativismo en la historia de la literatura económica. Ciriec-España, Revista de Economía Pública, Social y Cooperativa, (44), 9-32. Recuperado de http://www.redalyc.org/pdf/174/17404 40I.pdf

Mun, T. (1895). England's treasure by forraign trade. Nueva York: Macmillan.

Narváez-Rodríguez, C. (20I4). Asociaciones y cooperativas rurales: factores internos y externos que influyen en su estabilidad y eficiencia. Una reflexión sobre el caso de Viotá, Cundinamarca. Cooperativismo y Desarrollo, I04(22), 63-8I. http://dx.doi.org/I0.16925/co.v22iro4.97I

Pardo-Martínez, L. P., y Huertas-de-Mora, M. V. (20I4). La economía social, la economía solidaria y el tercer sector. En Tendencias en la gestión de empresas sin ánimo de lucro (pp. 49-57). Bogotá: Universidad Cooperativa de Colombia.

Pérez, J. C., Etxezarreta, E., y Guridi, L. (2009). Economía social, empresa social y economía solidaria: diferentes conceptos para un mismo debate. Papeles de Economía Solidaria-Ekonomia Solidarioaren Paperak, (I). Recuperado de http://base.socioeco.org/docs/papeles_es_I_reaseuskadi.pdf

Programa de las Naciones Unidas para el Desarrollo [PNUD], y Área de Desarrollo, Paz y Reconciliación [Redes]. (2012). Índice de capacidad organizacional (ICO). Guía de aplicación y análisis del índice de capacidad organizacional a las agencias de desarrollo económico local. Recuperado de http://www.ilsleda.org/usr_file s/activities_national/r2-guia_de_anal_424465.pdf

Real Academia Española [RAE]. (1992). Diccionario de la lengua española. Madrid: Espasa-Calpe.

Ricoy, C. (2006). Contribución sobre los paradigmas de investigación. Educação. Revista do Centro de Educação, 3I(I), II-22. Recuperado de http://www.redalyc.org/articulo.oa?id=II7II7257002

Rojas, P., y Sepúlveda, S. (1999). ¿Qué es la competitividad? Competitividad de la agricultura: cadenas agroalimentarias y el impacto del factor localización espacial. Series de Cuadernos Técnicos, (9). Recuperado de http://orton.catie.ac.cr/repdoc/A5283e/A5283e.pdf

Saavedra, M. L. (2012). Una propuesta para la determinación de la competitividad en la pyme latinoamericana. Revista Pensamiento y Gestión, (33), 93-124. Recuperado de http://www.redalyc.org/articulo.oa?id=6462486 7005

Sachs, J., y Vial, J. (2002). Competitividad y crecimiento económico en los países andinos y en América Latina. Borrador preliminar. Cambridge: Center for International Development, Harvard University.

Sachs, J., y Warner, A. M. (1995). Natural resource abundance and economic growth. National Bureau of Economic Research, Working Paper n.o 5398. Recuperado de https://www.nber.org/papers/w5398

Sachs, J., y Warner, A. M. (200I). The curse of natural resources. European Economic Review, 45, 827-838. Recuperado de http://www.earth.columbia.edu/sitefiles/file/about/director/pubs/EuroEconReview200I. pdf

Smith, A. (1776). Investigación de la naturaleza y causas de la riqueza de las naciones. Valladolid.

Solleiro, J. L., y Castañón, R. (2005). Competitividad y sistemas de innovación: los retos para la inserción de México en el contexto global. Globalización, Ciencia y Tecnología, I65-197.

Tamames, R. (1988). Diccionario de economía. Madrid: Alianza.

Thurow, L. (1985). The zero sum solution: Building a world class American economy. Simon and Schuster.

Ubfal, D. (2004). El concepto de competitividad. Medición y aplicación al caso argentino. Universidad de Buenos 
Aires, trabajo n.o 15. Recuperado de http://www.economicas.uba.ar/wp-content/uploads/2016/03/CENES I5.pdf

\section{Notas}

*Artículo de investigación

[I] La economía social es el estudio de todas aquellas formas organizativas e instituciones en las que prevalece el bien común frente a los intereses del mercado: tales formas son las asociaciones, empresas cooperativas y mutuales; por otro lado, la economía solidaria estudia las relaciones de producción, distribución, consumo y financiación basadas en la cooperación (Pardo-Martínez y Huertasde-Mora, 20I4).

Licencia Creative Commons CC-BY 4.0 